\title{
Bridging the channel: the first British Isles supplement of the European Spine Journal
}

\author{
Bronek Boszczyk $\cdot$ Phil Sell
}

Received: 2 March 2012/Published online: 20 March 2012

(C) Springer-Verlag 2012

This supplement is a first for the Spine Societies of the British Isles and the United Kingdom. Members have always had engagement with Europe, but this marks the start of a closer relationship with the Spine Society of Europe. The common bond of each National Spine Society has been the congress of scientific meeting with podium presentations, abstract publication and for some, subsequent peer reviewed publication. That will remain unique to each society.

The European Spine Journal has become firmly established as the premiere Spine journal for the European Community. With this first supplement we are proud to have taken a further step towards unifying medical professionals engaged in the study and surgery of spinal disorders across Europe. The manuscripts contained in this supplement were presented at the annual meetings of the Society for Back Pain Research (SBPR) and the British Association of Spine Surgeons (BASS). The range of clinical and basic science papers within this supplement reflects the breadth of research undertaken in the British Isles. Another first is the publication of the accepted abstracts of the bi-annual Britspine meeting synchronous

\footnotetext{
B. Boszczyk $(\bowtie) \cdot$ P. Sell

The Centre for Spinal Studies and Surgery, Queen's Medical Centre Campus, Nottingham University Hospitals NHS Trust, Derby Road, West Block D Floor, Nottingham NG7 2UH, UK e-mail: bronek.boszczyk@nuh.nhs.uk; B.Boszczyk@gmx.net

P. Sell

Department of Orthopaedics, University Hospitals of Leicester NHS Trust, Leicester, UK

e-mail: psell2.spine@tiscali.co.uk
}

with the event, and these abstracts are now available to a wider community than before.

The role of spine societies is changing, inevitably. The scientific community enables multidisciplinary approaches to problem-solving and advancement of knowledge. Professional groups also have needs and aspirations beyond the noble goal of sharing knowledge. Specialisation within health care professional groups has increased in the last three decades such that the treatment of certain spinal disorders has led to the speciality of spine surgery. Neurosurgical and orthopaedic papers in a non-partisan journal read by spine specialists is a step on that path to spine becoming a speciality in its own right. Specialist spine journals have a higher impact factor than non-specialist journals.

The role of societies is evolving to encompass education, training and research funding. To ignore the 'craft' or 'guild', aspect of professional practice is to risk isolation. The political dimension of the scientific spine societies within the European community is critical to the further development of the speciality of spinal surgery and the treatment of spinal disorders. Commercial organisations with intimate links to the medical industry lack credibility with the political bodies that validate and accredit health provision and training, and societies that fail to engage with the 'body politic' will never truly meet the needs of their membership.

The challenge put simply, is 'critical mass'. Some societies and some countries within Europe are simply very small to be heard. Representation at European level is more likely than not, to meet these needs. The Spine Society of Europe is leading with task forces on spinal research, a spine education program and the establishment of registers of surgical outcomes. The European Union of Medical Specialists (UEMS) has now established a multidisciplinary group for spinal disorders, possibly a first step 
to establishing standards for the speciality of Spine. The task is too great to be divided, and joined-up strategies have a greater chance of success for all of us in terms of future developments.
Acknowledgment We are grateful to D'fine for the sponsorship of this supplement.

Conflict of interest None. 